REVISTA

\title{
DISTRIBUIÇÃO ESPACIAL DA PRODUÇÃO AGROPECUÁRIA DO ESTADO DO ESPÍRITO SANTO: UMA ANÁLISE DOS SEGMENTOS FAMILIAR E NÃO FAMILIAR
}

\author{
SPACE DISTRIBUTION OF THE AGRICULTURE PRODUCTION OF \\ ESPÍRITO SANTO STATE: AN ANALYSIS OF FAMILY AND NON-FAMILY \\ SECTORS \\ ${ }^{1 *}$ Paulo Marcelo de Souza \\ ${ }^{2}$ Armando Fornazier \\ ${ }^{3}$ Niraldo José Ponciano

\footnotetext{
${ }^{1}$ Universidade Estadual do Norte Fluminense - UENF. Email:pmsouza@uenf.br

${ }^{2}$ Universidade de Brasília - UNB. Email: armandouenf@yahoo.com.br

${ }^{3}$ Universidade Estadual do Norte Fluminense - UENF. Email: ponciano@uenf.br

*Autor para correspondência
}

Artigo submetido em 31/07/2020, aceito em 14/10/2020 e publicado em 28/12/2020.

Resumo: As regiões do estado do Espírito Santo apresentam diferentes condições climáticas, de relevo, de estrutura fundiária, e foram marcadas por processos históricos de formação diferenciados. Disso resultam distintas dinâmicas produtivas regionais, em particular na agricultura. Com o uso de medidas de concentração, diversificação, especialização e localização, buscou-se caracterizar as diferenças regionais quanto à produção agropecuária do estado, considerando-se os segmentos familiar e não familiar. Os maiores índices de diversificação da produção agropecuária encontram-se na região central do estado, e são mais baixos na região Noroeste, cuja agricultura é baseada no cultivo do café. Foi constatada, também, a importância da agricultura familiar, principalmente nas regiões central e sul espírito-santense, onde representa mais de $80 \%$ dos estabelecimentos e mais de $50 \%$ do valor da produção.

Palavras-chave: economia regional; desigualdades; agricultura familiar.

Abstract: The regions of the Espírito Santo state present different conditions in terms of climate, relief and land structure, and were formed by different historical processes. This results in distinct regional productive dynamics, particularly in agriculture. In this research, using concentration, diversification, specialization and location measures, the objective was to characterize regional differences in agricultural production of Espírito Santo, considering family and non-family farmers. Significant regional differences were observed concerned to the considered measures. The highest diversification indexes are in the central region of the state. On the other hand, the lowest indexes occur in the Northwest region, where the agriculture is strongly based on cultivation of coffee. The results show the importance of family farming, mainly in the Central and South regions, where it represents more than $80 \%$ of establishments and more than $50 \%$ of the value of production.

Keywords: regional economy; inequalities; family farming. 


\section{INTRODUÇÃO}

Com área total de 46.074,444 km², o estado do Espírito Santo apresenta extensa faixa litorânea e regiões declivosas da Mata Atlântica, com uma diversidade de clima, relevo, solo e vegetação. No último Censo Demográfico, realizado em 2010, sua população era de 3.514.952 habitantes, dos quais 2.931.472 situavam-se no meio urbano $(83,4 \%)$ e 583.480 no meio rural (16,6\%) (IBGE, 2019).

Em termos de relevo, além da extensa área de litoral, o estado tem regiões com altas declividades. Conforme o Instituto Chico Mendes de Conservação e Biodiversidade (ICMBio), o estado abriga cerca de $80 \%$ do Parque Nacional do Caparaó, localizado na Serra do Caparaó, na divisa com Minas Gerais. No parque está presente o terceiro ponto mais alto do país, o Pico da Bandeira, que tem 2.892 metros de altitude (ICMBio, 2019). Diante disso, embora existam regiões com potencial para desenvolver uma agricultura mais mecanizada, em grande parte do estado destaca-se a agricultura familiar, cuja produção é mais intensiva no fator trabalho.

A essa diversidade se associam diferentes estratégias de desenvolvimento, relacionadas a distintos históricos de colonização. Os eventos históricos que culminaram na colonização deste estado contribuíram para consolidar uma estrutura produtiva, baseada na pequena propriedade e no trabalho familiar.

Entende-se que, por suas características, o segmento familiar tenha um importante papel na diversificação da produção agrícola do Espírito Santo, com especial participação na produção de alimentos. No entanto, análises mais detalhadas são necessárias para caracterizar a diversidade regional da produção agropecuária deste estado e investigar, em particular, se o segmento familiar exerce um papel diferenciado em termos de contribuição para a diversificação de sua agricultura.

Visando contribuir para entender tais dinâmicas, o presente estudo busca caracterizar os diferentes perfis regionais da produção agropecuária do Espírito Santo. Nessa caracterização, procura-se analisar as diferentes contribuições dos segmentos patronal e familiar. Com isso, espera-se gerar informações que contribuam para a elaboração de políticas voltadas para o desenvolvimento rural do estado e suas regiões.

\section{REFERENCIAL TEÓRICO}

A ocupação efetiva do território do Espírito Santo ocorreu no final da primeira metade do século XIX, com o desenvolvimento da cultura cafeeira. Esta cultura foi introduzida no estado no início do século XIX e se tornou, em meados do mesmo século, o principal produto de exportação da província, superando seu produto mais importante até então, a canade-açúcar (DARÉ, 2010). Segundo Macedo e Magalhães (2011), com a colonização estrangeira (italianos, alemães, açorianos, dentre outros) no final do século XIV, iniciou-se um processo de ocupação baseado principalmente na cultura do café, produzida dentro de uma estrutura de pequena propriedade rural familiar. Isso possibilitou à região capixaba romper com seu relativo isolamento territorial, demográfico e econômico, integrando-se, ainda que muito fragilmente, aos circuitos mercantis da economia brasileira.

A cafeicultura tem papel relevante na ocupação de todas as regiões do estado. No entanto, isso não significa dizer que essa ocupação foi um processo homogêneo, já que gerou distintas configurações produtivas regionais.

A colonização da região Sul do Espírito Santo ocorreu ao final da primeira metade do século XIX, propiciada pelo avanço da cafeicultura. Nessa época, após 
ultrapassar as fronteiras agrícolas fluminense e mineira, a produção de café migrou para o sul do Espírito Santo à procura de terras novas, reproduzindo nesta região a estrutura produtiva baseada na grande propriedade e no trabalho escravo (BERGAMIM, 2006).

Até o advento da cafeicultura, a região central desenvolvia a produção de cana-de-açúcar em grandes propriedades e com mão de obra escrava, mas possuía alguns poucos engenhos. Quando essa atividade foi substituída pelo café, em meados do século XIX, houve, em alguma medida, um processo de desconcentração da propriedade da terra (FERREIRA, 1987). Diferentemente do que ocorreu na região sul, marcada pela presença do grande fazendeiro, capitalizado e possuidor de escravos, na região central a figura marcante foi o imigrante europeu. No seu rastro, foram constituídas pequenas propriedades baseadas no trabalho familiar, que se tornaram o traço marcante dessa região (BERGAMIM, 2006).

Já a ocupação do norte do estado deu-se mais tarde, a partir do século XX, razão pela qual essa região praticamente não se beneficiou da política de colonização europeia, ocorrida na segunda metade do século anterior. Essa região foi colonizada por imigrantes oriundos de outras regiões do próprio estado, provenientes das regiões sul e central. A ocupação dessa região deu-se, inicialmente, em bases semelhantes às que marcaram as regiões central e sul: a pequena propriedade, o cultivo do café e o trabalho familiar. Posteriormente, com o crescimento da pecuária, observou-se aumento em seus índices de concentração fundiária (BERGAMIM, 2006).

Não obstante, os eventos ligados à colonização legaram ao Espírito Santo a posição de um dos estados com os melhores indicadores de distribuição de terra do país (SOUZA et al., 2015; HOFFMANN; NEY, 2010). Conforme Bergamim (2006), a constituição da pequena propriedade no estado, e por conseguinte, de sua agricultura familiar, está relacionada com dois acontecimentos históricos: a abolição da escravidão e a chegada do imigrante europeu. De um lado, a abolição contribuiu para desconcentrar a terra no sul do estado, visto que, diante da escassez de mão de obra, a maioria das fazendas dessa região tendeu a se fragmentar em pequenas propriedades. Por outro lado, nos núcleos oficiais de colonização, fundados pelo governo da província antes do fim da escravidão e localizados principalmente na região central, os imigrantes tiveram acesso à propriedade da terra, na qual trabalhavam com os membros da família.

É importante notar que a relevância histórica da cafeicultura no estado se mantém no presente. O Valor Bruto da Produção Agropecuária (VBPA) do estado, segundo estimativa de Galeano et al. (2018) para o ano de 2017, foi de 9,2 bilhões de reais. Conforme esses mesmos autores, a cafeicultura continua como destaque na agropecuária do estado, representando aproximadamente 38,9\% do valor de sua produção. Além desse produto, destacam-se ainda banana, mamão, tomate e pimenta-do-reino. Já no segmento da produção animal, responsável por quase $30 \%$ do valor da produção estadual, a produção de carne bovina, ovos, carne de aves e leite sãos as atividades mais representativas.

É esperado que a agricultura familiar tenha um papel importante na diversificação econômica da agricultura do Espírito Santo. Segundo Veiga (2000), a agricultura patronal mostra-se em geral mais competitiva que a familiar em alguns produtos, como carne bovina, soja, arroz e cana-de-açúcar, mas sua superioridade econômica é questionável para uma série de outras atividades. No caso da produção de frutas e hortaliças, em particular, a agricultura familiar tem condições para obter produtos com melhores índices de custo e qualidade. Ademais, a ênfase na diversificação é, em geral, uma estratégia 
característica da agricultura familiar (VEIGA, 1996).

Conforme Graziano da Silva (1999), a policultura é uma característica comum às diversas formas assumidas pela pequena produção no Brasil. Ainda que cultivem um produto principal, voltado para o mercado, esses agricultores se dedicam ao cultivo de vários outros produtos e à criação de animais: seja para comercializar ou simplesmente para a subsistência da família. Isso é corroborado pela análise de Guanziroli et al. (2001), que revela a predominância de produção mais diversificada entre os estabelecimentos familiares, ainda que haja estabelecimentos especializados.

\section{MATERIAIS E MÉTODOS}

3.1. Indicadores para caracterização da estrutura produtiva regional

Para caracterizar as diferenças regionais quanto ao perfil da produção, foram empregadas medidas de especialização e de localização. As medidas de localização são de natureza setorial e se preocupam com a localização das atividades entre as mesorregiões, ou seja, procuram identificar padrões de concentração ou dispersão da produção setorial, num determinado período. No presente caso, o coeficiente de localização foi utilizado nessa identificação. Já as medidas de especialização se concentram na análise da estrutura produtiva de cada mesorregião, objetivando analisar o grau de especialização das economias regionais num determinado período. Para esta análise, foram utilizados o índice de diversificação e o coeficiente de especialização. Além dessas medidas foram calculadas as razões de concentração ( $\mathrm{CR}_{4}$ e $\left.\mathrm{CR}_{8}\right)$, visando caracterizar a maior ou menor dependência das regiões quanto a produtos específicos. A seguir, faz-se breve descrição dessas medidas, tendo por base Haddad (1989), Lara, Fiori e Zanin (2010), Lima et al. (2006a), Lima et al. (2006b), Oliveira Filho et al. (2014).

Para o cálculo das medidas citadas as informações devem ser inicialmente organizadas em uma matriz que relaciona a distribuição setorial-espacial da variável base (Quadro 1). Tradicionalmente, a variável empregada em tais análises é o número de empregados por atividade. No entanto, diante da ausência de informações sobre o pessoal ocupado por atividade, foi empregada a variável valor da produção.

Nessa matriz, as colunas exibem a distribuição do valor da produção de determinada atividade entre as regiões, enquanto as linhas exibem a distribuição do valor da produção de dada região entre as diversas atividades que desenvolve. Essa matriz é composta pelos seguintes elementos:

$Q_{i j}=$ valor da produção da atividade $i$ da mesorregião $j$;

$\sum_{j} Q_{i j}=$ valor da produção da atividade $i$ do país;

$\sum_{i} Q_{i j}=$ valor da produção de todas as atividades da mesorregião $j$; $\sum_{i} \sum_{j} Q_{i j}=$ valor da produção total do país.

Quadro 1 - Matriz de informações geográfico-espaciais da distribuição do valor da produção

\begin{tabular}{|c|c|c|c|c|}
\hline $\begin{array}{c}\text { Distribuição } \\
\text { do valor da } \\
\text { produção }\end{array}$ & \multicolumn{2}{|c|}{ Mesorregiões (j) } & \multicolumn{2}{c|}{ Total } \\
\hline \multirow{2}{*}{$\begin{array}{c}\text { Atividades } \\
\text { (i) }\end{array}$} & $\leftarrow$ & $Q_{i j}$ & $\rightarrow$ & $\sum_{j} Q_{i j}$ \\
\cline { 2 - 5 } & & $\downarrow$ & & \\
\hline \multirow{2}{*}{ Total } & & $\sum_{i} Q_{i j}$ & & $\sum_{i} \sum_{j} Q_{i j}$ \\
\hline
\end{tabular}

Fonte: adaptado de Haddad, 1989 
A partir da matriz de informações são obtidas as medidas de localização e especialização ${ }^{1}$. São elas:

- Índice de diversificação

Para calcular o grau de diversificação produtiva regional foi empregado o índice de diversificação de Simpson $\left(I D_{j}\right)$. Esse índice é obtido por:

$$
I D_{j}=1-\sum_{i}\left(\frac{Q_{i j}}{\sum_{i} Q_{i j}}\right)
$$

Quanto mais especializada uma região, mais próximo de zero será esse índice. Quanto mais diversificada, mais próximo de um ele será.

\section{- Coeficiente de Especialização}

O coeficiente de especialização $\left(C E_{j}\right)$ é uma medida regional que compara a estrutura produtiva de dada região, com base participação de cada setor na produção total, com a estrutura produtiva de todo o estado. Ele é obtido pela soma, em módulo, das diferenças entre a participação do setor $i$ na produção total da região $j$ e a participação desse mesmo setor no estado. Seu cálculo é feito mediante a expressão:

$C E_{j}=\frac{\sum_{i}\left|\left(Q_{i j} / \sum_{i} Q_{i j}\right)-\left(\sum_{j} Q_{i j} / \sum_{i} \sum_{j} Q_{i j}\right)\right|}{2}$

Resultados iguais a 0 (zero) indicam que a mesorregião tem

\footnotetext{
1 Como essas medidas baseiam-se em variáveis de participação relativa, disparidades quanto ao tamanho das mesorregiões não afetam os resultados (LIMA et al., 2006b). Tratam-se, portanto, de medidas adequadas ao presente caso, visto que há diferenças entre regiões em termos de estabelecimentos, área, pessoal ocupado e valor da produção.
}

composição idêntica à do estado. Em contrapartida, coeficientes iguais ou próximos a 1 demonstram um elevado grau de especialização, associado a um determinado setor ou a uma estrutura produtiva muito diferente da estrutura produtiva do estado.

- Coeficiente de Localização

O coeficiente de localização $\left(C L_{i}\right)$ relaciona a distribuição de uma dada atividade entre as regiões com a distribuição do valor total da produção entre essas mesmas regiões. É estimado mediante somatório, em módulo, das diferenças entre a participação da mesorregião $j$ no setor $i$ do país, e a participação dessa região no total de setores do estado. É obtido pela equação:
$C L_{i}=\frac{\sum_{j}\left|\left(Q_{i j} / \sum_{j} Q_{i j}\right)-\left(\sum_{i} Q_{i j} / \sum_{i} \sum_{j} Q_{i j}\right)\right|}{2}$

(03)
Se o coeficiente de localização for igual a zero (0), significa que o setor $\mathrm{i}$ distribui-se regionalmente da mesma forma que o conjunto de todos os setores, ou seja, está mais disperso entre as mesorregiões. Se o valor for igual a um (1), o setor i apresenta um padrão de concentração regional mais intenso do que o conjunto de todos os setores.

- Razão de concentração

A razão de concentração $\left(\mathrm{CR}_{\mathrm{mj}}\right)$ foi empregada para determinar em que medida o valor da produção de dada região concentra-se em determinadas atividades. Esse índice foi calculado considerando-se a participação das quatro ou oito atividades mais importantes $\left(\mathrm{CR}_{4}\right.$ e $\left.\mathrm{CR}_{8}\right)$. Considerando-se um total de $n$ atividades, a razão de concentração das $m$ atividades mais importantes é calculada por: 


$$
C R_{m j}=\frac{\sum_{i=1}^{m} Q_{i j}}{\sum_{i=1}^{n} Q_{i j}}
$$

\subsection{Variáveis e fonte dos dados}

Foram consideradas todas as atividades que, em alguma região, tenham gerado valor de produção no ano de 2006. Procurou-se não somar os valores de produtos semelhantes, mas gerados por atividades distintas (por exemplo, leite de cabra e leite de vaca), nem o valor de produtos distintos gerados por uma mesma atividade (por exemplo, produção de aves e produção de ovos). O valor total da criação foi calculado somando-se o valor dos animais vendidos e abatidos ${ }^{2}$.

Com esses procedimentos, chegouse a um total de 151 atividades de produção agropecuária, extrativista ou agroindustrial. As informações foram obtidas no Sistema de Recuperação Automática (Sidra), do Instituto Brasileiro de Geografia e Estatística (IBGE), e têm por base os dados do Censo Agropecuário de 2006.

\section{RESULTADOS E DISCUSSÃO}

Na Tabela 1, pode-se notar que a produção agropecuária do Espírito Santo é relativamente bem distribuída entre suas regiões. As mesorregiões Central e Litoral Norte espírito-santense são as que possuem maior participação no valor da produção, e respondem conjuntamente por mais de $60 \%$ do valor da produção estadual. No

\footnotetext{
2 Seria desejável adicionar a esse montante a variação do inventário animal (obtido pela diferença entre o valor dos animais nascidos e comprados e o valor dos animais vitimados, vendidos e abatidos). Porém, como não há informação sobre o valor dos animais nascidos e vitimados, não foi possível acrescentar esse componente ao valor da produção animal.
}

entanto, são também elevadas as parcelas correspondentes às regiões Noroeste e Sul, que dividem entre si os quase $40 \%$ do valor restante da produção. Dentre as microrregiões, destacam-se Linhares, Afonso Cláudio, Santa Teresa e São Mateus, que concentram cerca de metade do valor da produção estadual. Por outro lado, são menores as parcelas das microrregiões de Barra de São Francisco, Itapemirim, Guarapari, Montanha e, sobretudo, Vitória.

\begin{tabular}{|c|c|c|c|c|}
\hline Região & Estabelecimentos & Área & Produção & Pessoal \\
\hline Noroeste Espírito-santense & 24,6 & 26,6 & 19,6 & 24,3 \\
\hline Barra de São Francisco & 6,8 & 9,0 & 3,6 & 5,9 \\
\hline Colatina & 8,8 & 9,3 & 7,9 & 8,5 \\
\hline Nova Venécia & 9,0 & 8,3 & 8,1 & 9,8 \\
\hline Litoral Norte Espírito-santense & 14,5 & 31,6 & 29,4 & 20,1 \\
\hline Linhares & 7,3 & 13,5 & 15,0 & 10,0 \\
\hline Montanha & 2,8 & 6,7 & 4,6 & 3,6 \\
\hline São Mateus & 4,4 & 11,3 & 9,8 & 6,5 \\
\hline Central Espírito-santense & 32,3 & 21,8 & 32,1 & 29,2 \\
\hline Afonso Cláudio & 13,1 & 8,3 & 14,1 & 12,6 \\
\hline Guarapari & 5,6 & 4,1 & 4,0 & 4,0 \\
\hline Santa Teresa & 12,1 & 7,4 & 12,6 & 11,2 \\
\hline Vitória & 1,5 & 2,0 & 1,4 & 1,4 \\
\hline Sul Espírito-santense & 28,5 & 20,0 & 18,9 & 26,4 \\
\hline Alegre & 12,9 & 8,1 & 7,2 & 12,2 \\
\hline Cachoeiro de Itapemirim & 12,2 & 9,6 & 7,8 & 11,0 \\
\hline Itapemirim & 3,4 & 2,4 & 3,9 & 3,2 \\
\hline Total & 100,0 & 100,0 & 100,0 & 100,0 \\
\hline
\end{tabular}

Constata-se que mais de $30 \%$ da área de estabelecimentos agropecuários concentrase na região Litoral Norte espíritosantense, o que ajuda a explicar sua significativa contribuição para o valor da produção. No entanto, essa é a região com menor participação no número de estabelecimentos e no pessoal ocupado, indício da presença de estabelecimentos maiores, com uso menos intensivo de mão de obra. Em situação oposta, encontra-se a mesorregião Central espírito-santense, com cerca de $20 \%$ da área de estabelecimentos agropecuários do estado, porém, representa cerca de $30 \%$ ou mais do número de estabelecimentos, do valor da produção e do pessoal ocupado. Trata-se, neste caso, de uma realidade marcada pela presença de estabelecimentos menores, mais intensivos de mão de obra, predominantemente familiares.

Na Tabela 2, observa-se que o segmento familiar do estado, com 34\% da área, responde por cerca de $80 \%$ dos 
estabelecimentos, 61\% do pessoal ocupado e $43 \%$ do valor da produção. Esse segmento tem maior expressão nas mesorregiões Central e Sul espíritosantense, onde representa mais de $80 \%$ dos estabelecimentos e mais de $50 \%$ do valor da produção. Nessas regiões, a agricultura familiar tem maior participação na área e na ocupação da mão de obra, que chega a quase $70 \%$ no caso da região Central.

Essa agricultura também é importante na região Noroeste espíritosantense, com grande participação no número de estabelecimentos, na produção e no pessoal ocupado, mas bem menos expressiva na região Litoral Norte. Nesta última, apesar de representarem cerca de $75 \%$ do número de estabelecimentos, os agricultores familiares ocupam apenas $17 \%$ da área, respondendo por parcela relativamente menor da produção e da mão de obra ocupada.

Com exceção das microrregiões de Linhares, Montanha, São Mateus e Vitória, onde a participação da agricultura familiar na área, na produção e na ocupação de mão de obra é menos expressiva, nas demais regiões esse segmento se destaca, respondendo por participações na faixa de $40-65 \%$ do valor da produção, $75-85 \%$ do número de estabelecimentos e $60-70 \%$ do pessoal ocupado.

\begin{tabular}{|c|c|c|c|c|}
\hline Região & Estabelecimentos & Área & Produção & Pessoal \\
\hline Noroeste Espírito-santense & 78,6 & 36,5 & 45,0 & 61,8 \\
\hline Barra de São Francisco & 81,0 & 31,3 & 49,0 & 71,3 \\
\hline Colatina & 79,4 & 39,8 & 44,5 & 59,3 \\
\hline Nova Venécia & 75,9 & 38,5 & 43,6 & 58,2 \\
\hline Litoral Norte Espírito-santense & 74,8 & 17,0 & 24,4 & 46,5 \\
\hline Linhares & 71,6 & 20,8 & 26,6 & 44,4 \\
\hline Montanha & 77,4 & 20,2 & 20,2 & 43,3 \\
\hline São Mateus & 78,5 & 10,6 & 23,0 & 51,4 \\
\hline Central Espírito-santense & 83,0 & 51,8 & 52,3 & 68,4 \\
\hline Afonso Cláudio & 83,1 & 56,9 & 57,6 & 66,0 \\
\hline Guarapari & 83,0 & 45,2 & 62,8 & 72,9 \\
\hline Santa Teresa & 84,6 & 60,0 & 45,7 & 72,0 \\
\hline Vitória & 68,8 & 13,9 & 29,7 & 47,8 \\
\hline Sul Espírito-santense & 80,2 & 38,3 & 53,9 & 63,2 \\
\hline Alegre & 82,5 & 44,3 & 57,0 & 65,6 \\
\hline Cachoeiro de Itapemirim & 76,1 & 35,8 & 44,8 & 58,1 \\
\hline Itapemirim & 86,2 & 28,0 & 66,5 & 72,1 \\
\hline Total & 79,9 & 34,0 & 43,0 & 61,0 \\
\hline
\end{tabular}

Em cerca de 65\% dos municípios a participação da agricultura familiar na produção é maior que $50 \%$, como pode ser notado na Figura 2. Essa proporção chega a de $85 \%$ dos municípios, quando consideradas as situações onde a agricultura familiar participa com mais de 40\% da produção agropecuária municipal.

Figura 2 - Distribuição dos municípios conforme a participação da agricultura familiar no valor da produção - Espírito Santo, 2006

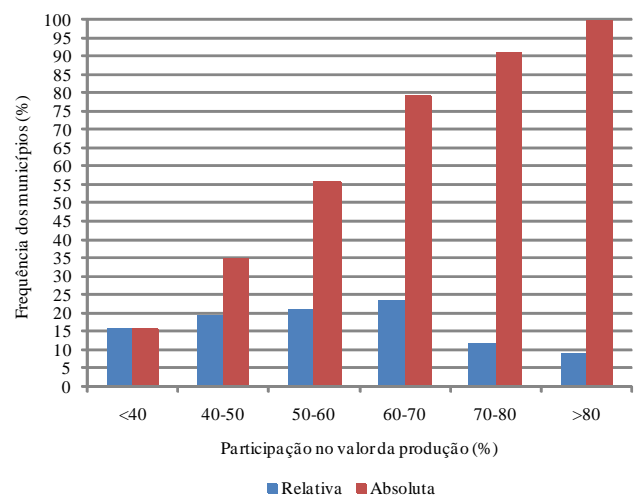

Fonte: Resultados da pesquisa.

Os maiores índices de produtividade do trabalho encontram-se na região Litoral Norte, especialmente nas microrregiões de Linhares e São Mateus (Tabela 3). Em situação oposta, encontrase a região Sul espírito-santense, que apresenta os índices mais baixos de produção por trabalhador, associados às microrregiões de Alegre e Cachoeiro de Itapemirim. No entanto, isso não ocorre na microrregião de Itapemirim, que se destaca pelo alto valor da produtividade do trabalho.

Por outro lado, na região Central a produtividade da terra é mais alta, o que está particularmente associado às microrregiões de Afonso Cláudio e Santa Tereza, que também se destacam por valores relativamente altos de produção por unidade de trabalho. Os índices mais baixos de produtividade da terra se encontram na região Noroeste do estado, e ocorrem principalmente na microrregião de Barra de São Francisco. Nestes casos, a produtividade do trabalho também é relativamente mais baixa.

Constata-se ainda que, na quase totalidade dos casos, a produtividade da terra é maior no segmento familiar da agricultura. A única exceção é a 
microrregião de Santa Teresa, onde esse indicador é mais elevado no segmento não familiar. Já a produtividade do trabalho é, sem exceções, maior no segmento não familiar.

Tabela 3 - Indicadores da produtividade da terra e do trabalho na agropecuária das regiões do estado do Espírito Santo, 2006

\begin{tabular}{|c|c|c|c|c|c|c|}
\hline & \multicolumn{3}{|c|}{ Produtividade da terra (R\$ha) } & \multicolumn{3}{|c|}{ Produtividade do trabalho (R\$/E.H.) } \\
\hline & N. Familiar & Familiar & Total & N. Familiar & Familiar & Total \\
\hline Noroeste Espirito-santense & 570,05 & 810,40 & 657,83 & $10.857,65$ & $5.493,92$ & 754,40 \\
\hline Barra de São Francisco & 269,65 & 568,55 & 363,22 & $10.215,39$ & $3.954,89$ & 575,30 \\
\hline Colatina & 700,05 & 849,18 & 759,44 & $11.824,47$ & $6.508,65$ & 867,10 \\
\hline Nova Venécia & 789,16 & 977,23 & 861,50 & $10.311,79$ & $5.736,36$ & 764,98 \\
\hline Litoral N. Espírito-santense & 757,32 & $1.189,98$ & 831,00 & $19.271,46$ & $7.164,22$ & $1.364,70$ \\
\hline Linhares & 915,88 & $1.262,02$ & 987,90 & $18.428,90$ & $8.349,13$ & $1.395,19$ \\
\hline Montanha & 609,04 & 610,59 & 609,36 & $16.639,59$ & $5.534,93$ & $1.183,25$ \\
\hline São Mateus & 667,98 & $1.675,21$ & 775,08 & $22.482,59$ & $6.345,80$ & $1.419,01$ \\
\hline Central Espírito-santense & $1.299,72$ & $1.330,52$ & $1.315,66$ & $15.512,47$ & $7.866,16$ & $1.028,18$ \\
\hline Afonso Cláudio & $1.497,85$ & $1.538,93$ & $1.521,22$ & $13.013,41$ & $9.083,59$ & $1.041,91$ \\
\hline Guarapari & 594,36 & $1.214,05$ & 874,65 & $12.925,31$ & $8.095,88$ & 940,36 \\
\hline Santa Teresa & $2.062,46$ & $1.158,63$ & $1.520,04$ & $20.392,99$ & $6.676,92$ & $1.051,35$ \\
\hline Vitória & 509,03 & $1.327,91$ & 623,08 & $13.023,33$ & $6.009,73$ & 967,27 \\
\hline Sul Espírito-santense & 627,92 & $1.182,95$ & 840,38 & $8.393,13$ & $5.699,57$ & 668,96 \\
\hline Alegre & 619,11 & $1.030,54$ & 801,38 & $6.909,86$ & $4.804,96$ & 552,98 \\
\hline Cachoeiro de Itapem. & 621,13 & 903,55 & 722,14 & $8.741,50$ & $5.112,89$ & 663,44 \\
\hline Itapemirim & 675,60 & $3.446,46$ & $1.451,59$ & $13.633,83$ & $10.450,25$ & $1.133,73$ \\
\hline Total & 771,65 & $1.126,74$ & 892,51 & $13.674,79$ & $6.583,31$ & 934,79 \\
\hline
\end{tabular}

Os maiores índices de diversificação da produção agropecuária encontram-se na região Central espíritosantense (Tabela 4). Esse resultado está particularmente associado à agricultura familiar dessa região, que apresenta maiores índices de diversificação da produção. Isso ocorre também em suas microrregiões, com exceção de Guarapari, e com maior intensidade na microrregião de Santa Teresa, onde a agricultura familiar apresenta índices de diversificação significativamente maiores.

Em situação oposta, encontra-se a região Noroeste, com os mais baixos índices de diversificação da produção, fato associado particularmente às microrregiões de Nova Venécia e Colatina. Na microrregião de Barra de São Francisco os índices são maiores, e também neste caso a contribuição do segmento familiar para a diversificação é importante.

Em situação intermediária encontram-se as regiões Litoral Norte e Sul espírito-santense, com índices de diversificação inferiores ao da região Central, porém significativamente mais elevados do que o estimado para a região Noroeste. No entanto, a região Sul se diferencia da região Norte por apresentar duas microrregiões, Alegre e Itapemirim, com baixos índices de diversificação.
Nessas regiões, há que se destacar ainda que, com exceção da microrregião de Montanha, nas demais a contribuição do segmento familiar para a diversificação agrícola apresenta-se inferior à do segmento não familiar.

\begin{tabular}{|c|c|c|c|}
\hline Região & Não familiar & Familiar & Total \\
\hline Noroeste Espírito-santense & 0,642 & 0,527 & 0,598 \\
\hline Nova Venécia & 0,535 & 0,400 & 0,481 \\
\hline Colatina & 0,572 & 0,426 & 0,514 \\
\hline Barra de São Francisco & 0,718 & 0,791 & 0,794 \\
\hline Litoral N. Espírito-santense & 0,844 & 0,604 & 0,820 \\
\hline São Mateus & 0,726 & 0,556 & 0,753 \\
\hline Montanha & 0,776 & 0,833 & 0,802 \\
\hline Linhares & 0,831 & 0,510 & 0,780 \\
\hline Central Espírito-santense & 0,847 & 0,885 & 0,889 \\
\hline Vitória & 0,818 & 0,881 & 0,872 \\
\hline Afonso Cláudio & 0,790 & 0,831 & 0,833 \\
\hline Guarapari & 0,859 & 0,849 & 0,883 \\
\hline Santa Teresa & 0,631 & 0,885 & 0,809 \\
\hline Sul Espírito-santense & 0,814 & 0,796 & 0,810 \\
\hline Itapemirim & 0,631 & 0,559 & 0,589 \\
\hline Alegre & 0,503 & 0,464 & 0,483 \\
\hline Cachoeiro de Itapemirim & 0,833 & 0,762 & 0,812 \\
\hline Total & 0,880 & 0,833 & 0,868 \\
\hline
\end{tabular}

Na Tabela 5 , pode-se constatar que cerca de 60 e 80 \% do valor da produção do Espírito Santo estão associados aos quatro $\left(\mathrm{CR}_{4}\right)$ e oito $\left(\mathrm{CR}_{8}\right)$ principais produtos de sua agricultura, respectivamente. $\mathrm{O}$ primeiro indicador mostra-se mais alto no segmento familiar, o que em princípio contraria a expectativa. No entanto, quando se consideram os oito principais produtos, a concentração é menor na agricultura familiar.

As razões de concentração mais baixas no segmento familiar ocorrem com particular intensidade na mesorregião Central espírito-santense, sobretudo nas microrregiões de Vitória e Santa Teresa, e nas microrregiões de Barra de São Francisco e Montanha, situadas nas mesorregiões Noroeste e Litoral Norte. A principal exceção é a microrregião de Linhares, que se destaca por apresentar uma agricultura mais diversificada no segmento não familiar, com índices expressivamente melhores do que os da agricultura familiar.

Fica evidente, conforme Tabela 6, a importância do cultivo de café no estado, cultura responsável por cerca de $44 \%$ do valor de sua produção agropecuária (espécies conilon e arábica). Outras atividades importantes são o cultivo da 
cana-de-açúcar, da banana e da madeira para papel e celulose e, na produção animal, a bovinocultura, de corte e leite, e a avicultura para corte e ovos.

As razões de concentração também ressaltam as diferenças marcantes no perfil da produção agropecuária das regiões Noroeste e Central do estado. Enquanto na primeira quase $90 \%$ do valor da produção está associado a apenas quatro produtos $\left(\mathrm{CR}_{4}\right)$, na segunda esse valor cai para cerca de $60 \%$. Nesta última, a participação dos oito principais produtos $\left(\mathrm{CR}_{8}\right)$ fica ainda abaixo dos $80 \%$ do valor total da produção.

\begin{tabular}{|c|c|c|c|c|c|c|c|}
\hline \multirow[b]{2}{*}{ Região } & \multicolumn{3}{|c|}{ CR4 } & \multicolumn{3}{|c|}{ CR8 } & \\
\hline & $\mathrm{NF}$ & $\mathrm{F}$ & $T$ & $\mathrm{NF}$ & $\mathrm{F}$ & $\mathrm{T}$ & \\
\hline Noroeste Espírito-santense & 89,8 & 87,5 & 88,8 & 94,6 & 92,1 & 93,4 & \\
\hline Nova Venécia & 90,2 & 90,1 & 89,5 & 96,5 & 94,6 & 94,8 & \\
\hline Colatina & 93,3 & 90,3 & 92,0 & 96,4 & 94,4 & 95,2 & \\
\hline Barra de São Francisco & 93,3 & 82,1 & 87,8 & 97,5 & 92,9 & 94,6 & \\
\hline Litoral N. Espírito-santense & 72,4 & 76,4 & 71,5 & 90,6 & 88,6 & 88,0 & \\
\hline São Mateus & 88,1 & 86,7 & 85,3 & 97,2 & 94,2 & 95,9 & \\
\hline Montanha & 87,7 & 75,2 & 81,7 & 98,1 & 93,6 & 97,0 & \\
\hline Linhares & 68,5 & 82,9 & 70,1 & 88,3 & 91,4 & 86,0 & \\
\hline Central Espírito-santense & 70,9 & 61,8 & 60,4 & 86,3 & 74,9 & 79,3 & \\
\hline Vitória & 74,3 & 61,7 & 62,4 & 94,0 & 80,5 & 88,9 & \\
\hline Afonso Cláudio & 76,3 & 73,6 & 71,3 & 88,9 & 83,8 & 84,7 & \\
\hline Guarapari & 65,6 & 70,1 & 61,4 & 89,6 & 82,4 & 82,8 & \\
\hline Santa Teresa & 83,7 & 58,8 & 71,6 & 91,0 & 68,8 & 79,4 & \\
\hline Sul Espírito-santense & 75,8 & 76,2 & 73,8 & 91,9 & 89,6 & 90,4 & \\
\hline Itapemirim & 94,4 & 96,5 & 94,1 & 99,5 & 99,1 & 99,2 & \\
\hline Alegre & 92,7 & 86,4 & 89,1 & 96,0 & 93,1 & 94,2 & \\
\hline Cachoeiro de Itapemirim & 77,7 & 81,6 & 79,5 & 92,4 & 91,4 & 91,9 & \\
\hline Total & 58,3 & 65,4 & 59,7 & 82,3 & 78,7 & 78,3 & \\
\hline
\end{tabular}

Na região Noroeste, a produção de café conilon é a principal atividade, seguida pela criação de bovinos para corte e leite (Tabela 6). Na microrregião de Colatina, quase $80 \%$ do valor da produção está associado à lavoura de café, considerando-se as duas espécies cultivadas. Também na microrregião de Nova Venécia o cultivo do café responde, isoladamente, por cerca de $70 \%$ do valor total da produção. A cafeicultura também é importante na microrregião de Barra do São Francisco, mas nesta região a bovinocultura, nas modalidades carne e leite, assume importância relativamente maior.

Já na região Central do estado, além da produção de café, que representa cerca de um terço do valor da produção, destacam-se ainda os cultivos de banana e tomate. No entanto, há forte participação da produção animal, sobretudo da avicultura para corte e ovos, além da bovinocultura e da criação de suínos.
Tabela 6 - Principais produtos (responsáveis por 80\% ou mais da produção), e respectivas participaç̃ões no valor da produção, de cada microrregião geográfica do Espírito Santo, 2006

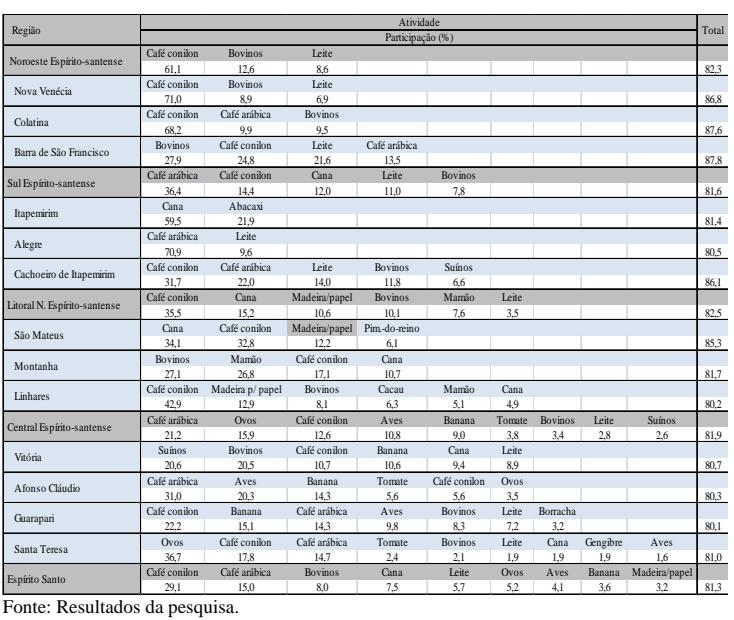

A produção de café tem elevada participação nas agriculturas de Afonso Cláudio, Guarapari e Santa Teresa. Nesta, no entanto, a produção animal tem grande relevância, destacando-se a produção de ovos, além da criação de bovinos para corte e leite. A avicultura, principalmente para corte, é também uma atividade importante nas microrregiões de Afonso Claudio e Guarapari, sendo que nesta destaca-se também a bovinocultura para corte e leite. Já a produção de suínos concentra-se na microrregião de Vitória, onde também é importante a criação de bovinos (corte e leite).

Outra atividade de grande relevância na região é a produção de banana, importante nas microrregiões de Afonso Claudio, Guarapari e Vitória, além da produção de cana (Vitória) tomate (Afonso Claudio e Santa Teresa), borracha (Guarapari) e gengibre (Santa Teresa).

Já as regiões Litoral Norte e Sul do estado apresentam índices intermediários, com $\mathrm{CR}_{4}$ e $\mathrm{CR}_{8}$ próximos de $70 \%$ e $90 \%$, respectivamente. No entanto, na região Sul esses índices são mais altos nas microrregiões de Alegre e Itapemirim, onde cerca de $90 \%$ ou mais do valor da produção está associado a apenas quatro produtos. Na Litoral Norte, as razões de concentração são mais elevadas nas microrregiões de São Mateus e Montanha, onde quatro produtos respondem por cerca de $80-85 \%$ do valor total da produção. 
Metade do valor da produção da região Sul espírito-santense está associada ao cultivo de café, especialmente da espécie arábica. Outras atividades importantes são o cultivo de cana e a pecuária bovina, para corte e leite. A produção de café responde por cerca de 50 e $70 \%$ do valor da produção das microrregiões de Cachoeiro de Itapemirim e Alegre, respectivamente. Nessas regiões, a bovinocultura (Cachoeiro de Itapemirim e Alegre) e a criação de suínos (Cachoeiro de Itapemirim) são também atividades importantes. Já a agricultura da microrregião de Itapemirim se distingue das demais por se concentrar na produção de cana e abacaxi.

A produção de café, nesse caso o conilon, é também a principal atividade da região Litoral Norte espírito-santense, onde também são importantes a produção de cana, mamão e madeira para papel, além da criação de bovinos para corte e leite. A cafeicultura é importante em todas as regiões, mas principalmente em Linhares e São Mateus. Na primeira destacam-se ainda a produção de madeira para papel, cacau, mamão e cana, além da pecuária de corte. Na segunda, além da produção de cana e madeira, tem relevância o cultivo da pimenta-do-reino. Já na região de Montanha, onde também são importantes as culturas de café e cana, destacam-se principalmente a pecuária de corte e a produção de mamão.

Há poucas diferenças entre as mesorregiões quanto aos coeficientes de especialização (Tabela 7), o que em parte se explica pelo efeito conjunto das diferentes estruturas produtivas das microrregiões que as compõem. No entanto, quando consideradas as microrregiões, Alegre e Itapemirim apresentam os maiores coeficientes de especialização, indicando uma diferença maior entre as estruturas produtivas dessas regiões e a do estado como um todo.

Tabela 7 - Coeficiente de especialização regional da produção agropecuária do Espírito
\begin{tabular}{l|c|c|c|}
\hline Santo, 2006 & Não familiar & Familiar & Total \\
\hline Região & 0,412 & 0,407 & 0,406 \\
\hline Noroeste Espírito-santense & 0,464 & 0,490 & 0,468 \\
\hline Nova Venécia & 0,409 & 0,436 & 0,413 \\
\hline Colatina & 0,516 & 0,277 & 0,374 \\
\hline Barra de São Francisco & 0,311 & 0,455 & 0,361 \\
\hline Litoral Norte Espírito-santense & 0,493 & 0,477 & 0,460 \\
\hline São Mateus & 0,516 & 0,555 & 0,552 \\
\hline Montanha & 0,344 & 0,523 & 0,384 \\
\hline Linhares & 0,471 & 0,323 & 0,402 \\
\hline Central Espírito-santense & 0,599 & 0,517 & 0,554 \\
\hline Vitória & 0,602 & 0,478 & 0,552 \\
\hline Afonso Cláudio & 0,490 & 0,272 & 0,321 \\
\hline Guarapari & 0,550 & 0,343 & 0,445 \\
\hline Santa Teresa & 0,411 & 0,385 & 0,382 \\
\hline Sul Espírito-santense & 0,724 & 0,850 & 0,794 \\
\hline Itapemirim & 0,659 & 0,583 & 0,625 \\
\hline Alegre & 0,371 & 0,236 & 0,299 \\
\hline Cachoeiro de Itapemirim & & & \\
\hline Fonte: Resultados da pesquisa. & &
\end{tabular}

Como visto anteriormente, a agricultura de Alegre concentra-se na produção de café, no entanto, distingue-se das demais regiões por ser predominantemente arábica. Itapemirim, por sua vez, distingue-se do restante do estado por apresentar uma agricultura calcada na produção de cana e abacaxi, culturas que não atingem tamanha expressão nas demais regiões. Em situação oposta encontra-se a microrregião de Cachoeiro de Itapemirim, com o mais baixo índice de especialização. A produção agropecuária dessa região, que se distribui principalmente entre os cultivos de café conilon e arábica e a pecuária de corte e leite, se assemelha ao que ocorre com a média do estado, onde essas atividades são em geral importantes.

Observa-se ainda que, no geral, os coeficientes de especialização tendem a ser menores no segmento familiar. A tendência de menor especialização das regiões no segmento familiar pode estar associada à importância que muitos produtos têm na alimentação dos agricultores. Isso também ajuda a explicar os melhores índices de diversificação observados para esse segmento. No segmento não familiar, a localização das atividades resulta de vantagens comparativas de determinadas regiões, associadas às condições edafoclimáticas, de relevo, de localização, de infraestrutura de transportes, dentre outras, que se traduzem numa produção mais competitiva. Na agricultura familiar, a produção de determinados produtos para autoconsumo pode ainda ser interessante 
mesmo em regiões onde aquelas vantagens não estão presentes, uma vez que o custo de produção, ainda que não competitivo para a venda, pode resultar inferior ao custo de aquisição desse mesmo produto no mercado.

Outra questão se refere às diferenças na dotação de recursos e seus efeitos sobre a escolha do que produzir. No segmento patronal, nas localidades com relevo adequado, o leque de atividades possíveis é maior, dada a possibilidade de mecanização das atividades e redução do emprego da mão de obra. Em relevos acidentados esse leque diminui, já que a mecanização não é possível, e a tendência é a opção por atividades pouco intensivas em mão de obra, como a pecuária extensiva e a silvicultura. No segmento familiar, supondo menores a escassez e o custo da mão de obra, a produção de determinadas atividades em regiões com relevo acidentado contorna em alguma medida essa limitação com um processo produtivo mais intensivo em trabalho.

Por conta desses fatores, entende-se que a distribuição regional das atividades no segmento familiar tende a uma menor rigidez, com índices de especialização mais baixos ${ }^{3}$. Pela mesma razão, em uma dada região a produção da agricultura familiar tende a ser mais diversificada, sobretudo se, por condições de relevo ou disponibilidade de mão de obra, as opções do segmento não familiar tornarem-se limitadas a produtos menos intensivos nesse fator.

O coeficiente de localização, exibido na Tabela 8, evidencia que a bovinocultura para a produção de carne é a atividade mais disseminada entre os diversos municípios do estado. O mesmo ocorre com a produção do café conilon, de

3 Essa é uma importante característica da agricultura familiar, uma vez que as condições para o exercício de uma agricultura intensamente mecanizada não estão presentes em todos os estados e municípios brasileiros. Nestes casos, em especial, o desenvolvimento de uma agricultura mais produtiva e diversificada passa, necessariamente, pelo apoio à agricultura familiar. madeira (outra finalidade) e de milho, além da pecuária leiteira, todas as atividades com coeficientes de localização relativamente baixos. Em situação oposta encontra-se a produção de abacaxi, com o maior coeficiente de localização. Além dessa cultura, destacam-se ainda a produção de ovos, cacau, pimenta do reino e madeira para papel, com altos coeficientes de localização.

Tabela 8 - Coeficiente de localização das principais atividades agropecuárias ${ }^{4}$ do Espírito Santo, 2006

\begin{tabular}{|c|c|c|}
\hline Produto & Particip. no valor da produção (\%) & Coeficiente de localização \\
\hline Café conilon & 29,21 & 0,309 \\
\hline Café arábica & 15,01 & 0,457 \\
\hline Bovinos & 7,97 & 0,287 \\
\hline Cana-de-açúcar & 7,53 & 0,611 \\
\hline Leite & 5,67 & 0,347 \\
\hline Ovos & 5,24 & 0,753 \\
\hline Aves & 4,07 & 0,620 \\
\hline Banana & 3,58 & 0,580 \\
\hline Madeira (papel) & 3,25 & 0,728 \\
\hline Mamão & 2,31 & 0,671 \\
\hline Suínos & 1,64 & 0,480 \\
\hline Tomate & 1,47 & 0,542 \\
\hline Cacau & 1,04 & 0,763 \\
\hline Abacaxi & 0,85 & 0,929 \\
\hline Pimenta-do-reino & 0,78 & 0,737 \\
\hline Milho & 0,77 & 0,380 \\
\hline Coco-da-baía & 0,70 & 0,451 \\
\hline Madeira (outra finalidade) & 0,68 & 0,344 \\
\hline Mandioca & 0,65 & 0,582 \\
\hline Borracha (látex coagulado) & 0,51 & 0,635 \\
\hline
\end{tabular}

Fonte: Resultados da pesquisa.

Na Tabela $9^{5}$, onde são apresentadas as principais regiões produtoras das vinte atividades mais importantes do estado, nota-se que a produção de abacaxi, cacau e ovos tem estreita relação com regiões específicas, como já indicado pelo coeficiente de localização. A quase totalidade desses produtos é gerada nas regiões de Itapemirim (abacaxi), Linhares (cacau) e Santa Teresa (ovos). Outras atividades bastante concentradas espacialmente são o cultivo de madeira para papel, pimenta-doreino e mamão, além da criação de aves de corte. A produção desses bens concentra-se nas regiões de Linhares e São Mateus

4 As atividades consideradas representam aproximadamente 93\% do valor da produção agropecuária do estado (cerca de $89 \%$ do segmento familiar e 96 \% do não familiar), e uma faixa que vai de um mínimo de $83 \%$ (Santa Teresa) a até $98 \%$ (Itapemirim) do valor produzido em cada microrregião.

5 Nessa tabela são apresentadas as regiões responsáveis por $80 \%$ ou mais do valor de cada atividade. 
(madeira), São Mateus e Nova Venécia (pimenta), Montanha e Linhares (mamão) e Afonso Claudio e Linhares (aves).

Já a criação de bovinos, visando carne ou leite, destaca-se como atividade disseminada por várias regiões do estado. Também a produção de mandioca e do café conilon são atividades relativamente dispersas regionalmente, com número significativo de regiões participando do valor total gerado no estado.

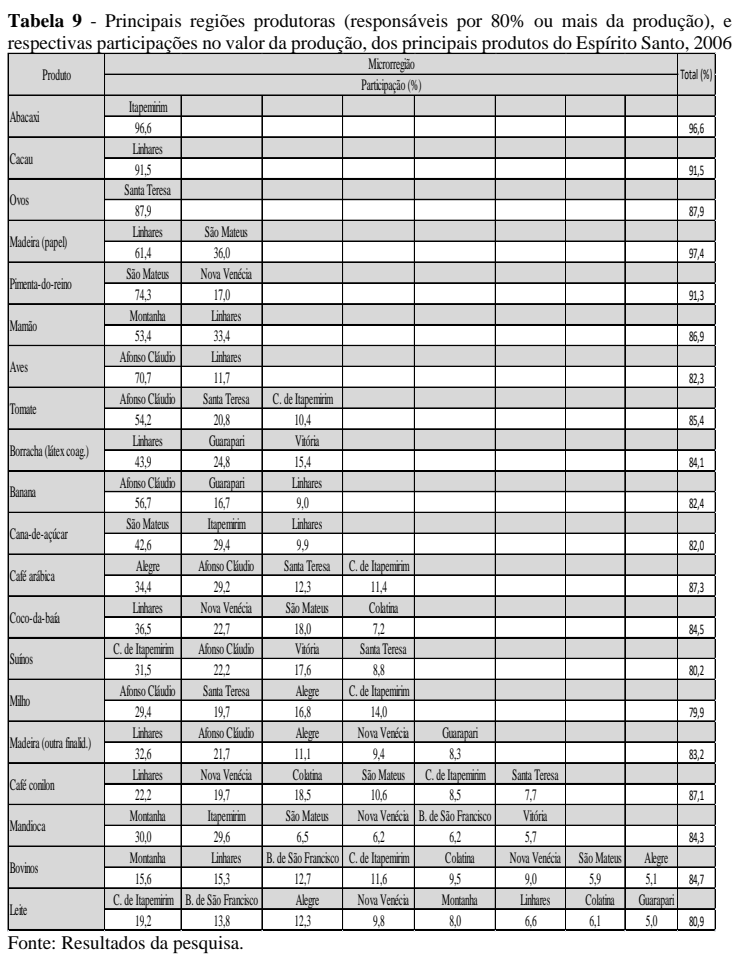

Na Figura 3, pode-se notar que a agricultura familiar tem participação igual ou superior ao segmento patronal em nove dos principais produtos da agropecuária espírito-santense (cafés arábica e conilon, pimenta-do-reino, tomate, milho, mandioca, madeira (outra finalidade), abacaxi e banana). A contribuição desse segmento é também expressiva (em torno da faixa de $30-40 \%$ ) na produção de canade-açúcar, coco, aves, suínos e leite, principalmente quando se considera que, como visto anteriormente, a agricultura familiar ocupa apenas 34\% da área de estabelecimentos agropecuários do estado. Por outro lado, a produção de madeira para papel, mamão, cacau, borracha, ovos e bovinos para corte pode ser caracterizada como de natureza predominantemente não familiar. Nesses casos, $80 \%$ ou mais do valor produzido ser origina nesse segmento.

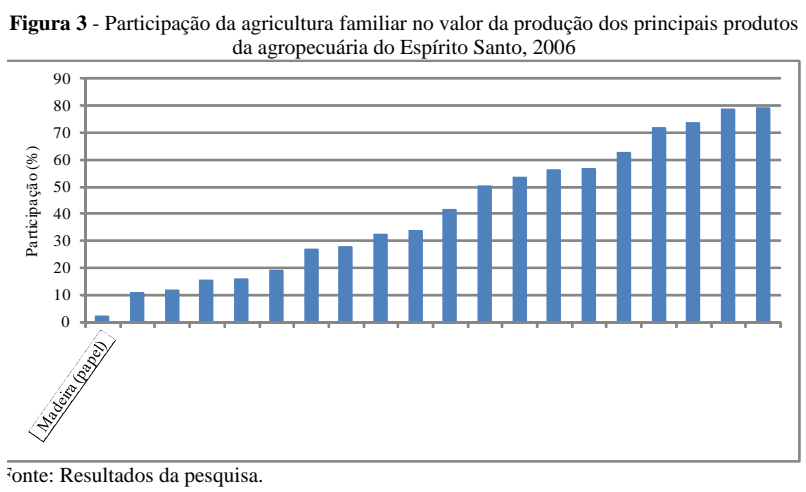

Assim, verifica-se que mesmo algumas atividades tendo uma maior importância na economia do estado como o café descrito por Galeano et al. (2018), quando se observa os dados por regiões e por segmentos familiar e não familiar, outras atividades possuem uma grande relevância. Assim, estudos como este se justificam pela importância de seconhecer essas peculiaridades na distribuição produtiva.

\section{CONCLUSÕES}

$\mathrm{Na}$ presente pesquisa, buscou-se avaliar a distribuição regional da produção agropecuária

espírito-santense, distinguindo-se os segmentos familiar e não familiar. Observou-se que a produção do estado é relativamente bem distribuída entre suas regiões. No entanto, destacam-se as microrregiões de Linhares, Afonso Cláudio, Santa Teresa e São Mateus, que concentram cerca de metade do valor da produção estadual.

A maioria dos estabelecimentos agropecuários do estado é de natureza familiar, respondendo por cerca $43 \%$ do valor da produção e $61 \%$ do pessoal ocupado, ainda que ocupem apenas 34\% da área total. Esse segmento tem especial importância nas mesorregiões Central e Sul espírito-santense, onde representa mais de $80 \%$ dos estabelecimentos e mais de $50 \%$ 
do valor da produção, mas tem importância relativamente menor na região Litoral Norte. Entende-se que os processos históricos relacionados à conformação da estrutura fundiária dessa região legaram à agricultura familiar uma menor participação em suas terras, reduzindo sua importância econômica.

Com tais características, a região Litoral Norte desenvolve uma agricultura menos intensiva no fator trabalho, com maiores índices de produtividade da mão de obra, especialmente nas microrregiões de Linhares e São Mateus. Já a região Sul do estado apresenta os mais baixos índices de produção por trabalhador, principalmente nas microrregiões de Alegre e Cachoeiro de Itapemirim.

Quanto à produtividade da terra, seu valor é mais elevado na região Central, sobretudo nas microrregiões de Afonso Cláudio e Santa Teresa. Os índices mais baixos desse indicador encontram-se na região Noroeste do estado, e ocorrem principalmente na microrregião de Barra de São Francisco, fato possivelmente associado à importância que assume nessa região a pecuária de corte, uma atividade de natureza extensiva. Constata-se ainda que, na quase totalidade dos casos, a produtividade da terra é maior no segmento familiar da agricultura, enquanto o segmento não familiar destaca-se por maior produtividade do trabalho.

Os maiores índices de diversificação da produção agropecuária encontram-se na região Central do estado, com forte presença da agricultura familiar. Por outro lado, os índices mais baixos de diversificação agrícola estão na região Noroeste, fato associado particularmente às microrregiões de Nova Venécia e Colatina, onde a agricultura é fortemente baseada no cultivo do café conilon.

$\mathrm{O}$ produto mais importante da agricultura do Espírito Santo é o café, responsável por cerca de $44 \%$ do valor de sua produção agropecuária (espécies conilon e arábica). Outras culturas importantes são a cana-de-açúcar, a banana e a madeira para papel. Na produção animal destacam-se a bovinocultura, de corte e leite, e a avicultura para corte e ovos. Juntas, essas atividades respondem por mais de $80 \%$ do valor da produção agropecuária do estado. Considerando-se outras atividades importantes, como a criação de suínos e a produção de mamão, tomate, cacau, abacaxi, pimenta-do-reino e milho, chega-se a $90 \%$ do valor da produção estadual.

Mostrou-se ainda que a agricultura familiar possui participação expressiva na geração desses produtos, com exceção da produção de madeira para papel, de mamão, de cacau, de ovos e de bovinos para corte. Na ausência de tal segmento, a agricultura do estado, em especial nas regiões menos propícias ao desenvolvimento de uma agricultura intensiva em capital, estaria confinada a um número restrito de atividades. Em síntese, os resultados apontam no sentido de reafirmar a importância do segmento familiar para o desenvolvimento rural.

\section{REFERÊNCIAS}

ALMADA, V. P. A escravidão na história econômico-social do Espírito Santo 1850-1888. 1981. Dissertação (Mestrado) Centro de Estudos Gerais, Universidade Federal Fluminense, Niterói, 1981.

BERGAMIM, M. C. A pequena propriedade rural no Espírito Santo: constituição e crise de uma agricultura familiar. In: CONGRESSO DA SOCIEDADE BRASILEIRA DE ECONOMIA, ADMINISTRAÇÃO E SOCIOLOGIA RURAL, 44., 2006, Fortaleza. Anais... Brasília, DF: SOBER, 2006.

DARÉ, R. A “crise” do café e a ideologia desenvolvimentista no espírito santo. Dissertação (Mestrado em Geografia), Centro de Ciências Humanas e Naturais, Universidade Federal do Espírito Santo, Vitória, 2010. 203p. 
FERREIRA, S. P. Espírito Santo: dinâmica cafeeira e integração no mercado nacional - 1940- 1960. 1987. Dissertação (Mestrado em Ciências), Instituto de Economia Industrial, Universidade Federal do Rio de Janeiro, Rio de Janeiro, 1987. 2 61f.

GALEANO, E. A. V. et al. Valor Bruto da Produção de 2017 e atualização das estimativas para a produção agrícola de 2018. Boletim da Conjuntura Agropecuária, Ano IV, n. 15, setembro de 2018. Instituto Capixaba de Pesquisa, Assistência Técnica e Extensão Rural Incaper.

GRAZIANO DA SILVA, J. A modernização conservadora dos anos 70. In: GRAZIANO DA SILVA, J. Tecnologia e agricultura familiar. Porto Alegre: Universidade/UFRS, 1999. p. 87-135.

GUANZIROLI, C. et al. Agricultura familiar e reforma agrária no século XXI. Rio de janeiro: Garamond, 2001. 288p.

HADDAD, J. H. (Org.). Economia regional: teoria e métodos de análise. Fortaleza: BNB/ETIENE, 1989.

HOFFMANN, R.; NEY, M. G. Estrutura fundiária e propriedade agrícola no Brasil, grandes regiões e unidades da federação. Brasília: Ministério do Desenvolvimento Agrário, 2010. 108p.

INSTITUTO BRASILEIRO DE GEOGRAFIA E ESTATÍSTICA - IBGE. Sistema de recuperação automática de dados-SIDRA. Disponível em: www.sidra.gov.br.. Acesso em: 08 jun. 2018.

Cidades. Brasil. Espírito Santo. Disponível em: https://cidades.ibge.gov.br/ brasil/ es/panorama. Acesso em: 30 mar. 2019.

INSTITUTO CHICO MENDES DE CONSERVAÇÃO E BIODIVERSIDADE - ICMBio. Parque Nacional do Caparaó.
Disponível

em: http://www.icmbio.gov.br/parnacaparao/. Acesso em: 30 mar. 2019.

LARA, F. M.; FIORI, T. P.; ZANIN, V. Notas sobre medidas de concentração e especialização: um exercício preliminar para o emprego no Rio Grande do Sul. Porto Alegre: Fundação de Economia e Estatística Siegfried Emanuel Heuser, 2010, 24p. (Textos para Discussão N. 83)

LIMA, J. F. et al. Análise regional das mesorregiões do estado do Paraná no final do século XX. Revista Análise Econômica, Porto Alegre, n. 46, p. 7-26, set. 2006a.

LIMA, J. F. et al. O uso das terras no sul do Brasil: uma análise a partir de indicadores de localização. Revista de Economia e Sociologia Rural, v. 44, n. 4, Brasília, out./dez. 2006b.

MACEDO, F. C.; MAGALHÃES, D. F. Formação econômica do Espírito Santo: do isolamento econômico à inserção aos mercados nacional e internacional. Revista de História Regional, v. 16, n. 1, p. 61-99, 2011.

OLIVEIRA FILHO et al. S. F. S. Adoção de estratégias para redução de riscos: identificação dos determinantes da diversificação produtiva no Polo PetrolinaJuazeiro. Revista de Economia e Sociologia Rural, Piracicaba, v.52, n.1, p. 117-138, jan./mar. 2014.

SOUZA, P. M. et al. Comportamento da distribuição do valor da produção vegetal entre os estabelecimentos agropecuários: uma análise dos dados dos censos de 1995/96 e 2006. Revista Econômica do Nordeste, Fortaleza, v. 46, n. 1, p. 131150, jan./mar., 2015.

VEIGA, J. E. Agricultura Familiar e Sustentabilidade. Cadernos de Ciência e Tecnologia. v. 13, n. 3, p. 383-404, 1996. 